\title{
34 \\ Using Multiagent Systems to Develop Individual-Based Models for Copepods: Consequences of Individual Behavior and Spatial Heterogeneity on the Emerging Properties at the Population Scale
}

\author{
Sami Souissi, Vincent Ginot, Laurent Seuront, and Shin-Ichi Uye
}

\section{CONTENTS}

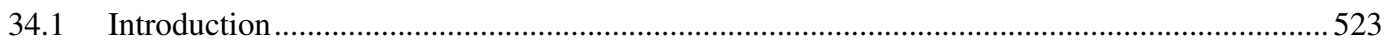

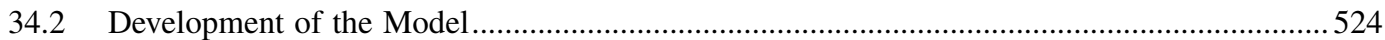

34.2.1 Main Characteristics of the Mobidyc Platform......................................................5 524

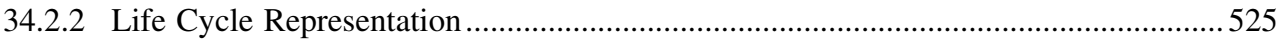

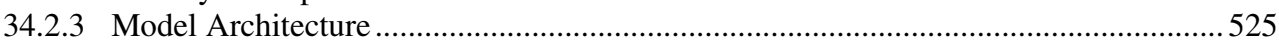

34.2.3.1 Modeling Survival, Growth, and Molting of Individuals ..........................527

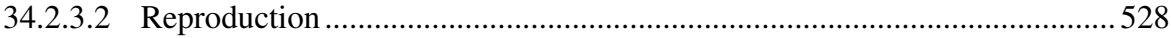

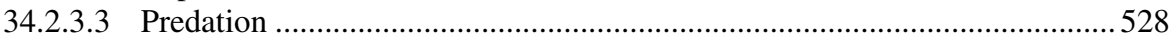

34.2.3.3.1 Effect of Body Weight and Temperature on the Ingestion Rate.... 528

34.2.3.3.2 The Predation Task ............................................................ 528

34.3 Results

.......528

34.3.1 Simulation of the Mortality of a Single Stage: Role of the Demographic Noise ...... 528

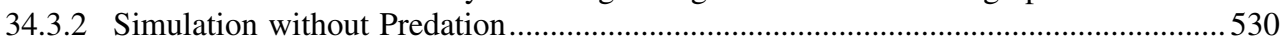

34.3.3 Effect of Cannibalism and Spatial Representation .................................................. 530

34.3.4 Effect of Predation on the Spatiotemporal Dynamics of the Population................... 530

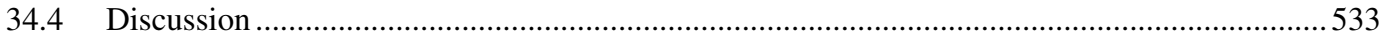

34.4.1 Toward an Improvement of Individual-Based Models ............................................ 534

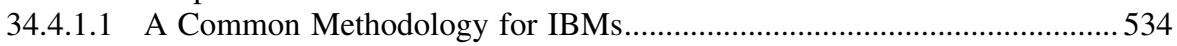

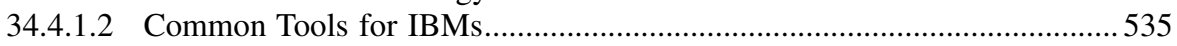

34.4.1.3 Common Languages and Common Descriptions for IBMs .....................536

34.4.2 IBMs and Population Dynamics of Zooplankton ......................................................5 536

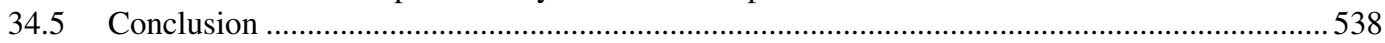

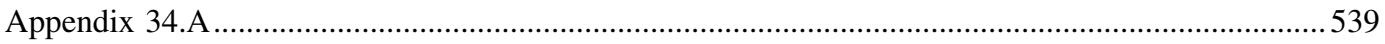

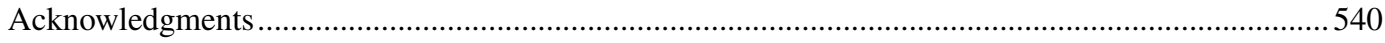

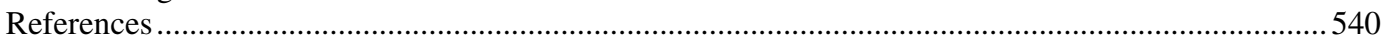

\subsection{Introduction}

In marine ecosystems the production of planktonic copepods supports most food webs, directly affecting higher trophic levels (including pelagic fish populations) and the biological pump of carbon into the deep ocean. ${ }^{1}$ Traditionally, in ecological models dealing with pelagic processes, the lowest trophic 
levels have been represented with functional groups. Except when size is treated explicitly, these models assume that all individuals within a trophic compartment are identical. ${ }^{2}$ Hence, the prevailing approach in observing and modeling pelagic populations is to characterize average processes (such as feeding, birth, growth, migration, and mortality) that are acting on total abundances or on spatially distributed fields of concentrations. ${ }^{3-5}$ However, several studies have shown that zooplankters, including copepods, possess individual traits and behaviors; ${ }^{6-8}$ consequently they act and react individually. Furthermore, the individuals may encounter different patterns of food and physical parameters, which may increase the inter-individual variability. ${ }^{9}$ At the population level the individual variability on the molting rate of copepods was observed from experimental work. ${ }^{10,11}$ The new emerging individual-based modeling (IBM) techniques are appropriate to cope with such variability. ${ }^{12}$ The success of this approach can be attributed to the fact that IBMs make more realistic assumptions than the more traditional state variable models.

The IBM is a "bottom-up" approach, and may be opposed to the classical state variable modeling, which is a "top-down" approach. ${ }^{13,14}$ Uchmański and Grimm ${ }^{15}$ defined individual-based models as models that should include discrete individuals with their complete life cycles as well as differences between individuals, and the dynamics of the resources (in general with spatial heterogeneity) over which the individuals compete. A corollary to this definition, which is a fundamental aspect of IBM, is the explicit representation of individual variability ${ }^{16}$ The differences among individuals affect the dynamics of the population. The interactions between individuals and/or their environment lead to global properties at the population level and/or at large spatial scales. This property referred to as "emergence" represents another fundamental concept of the IBM approach. ${ }^{17}$

The last decade (1990s) has been characterized by an exponential increase in the number of publications using IBMs in ecology.$^{18}$ Certainly the increase in computer power and the development of object computer languages and associated tools as simulators have significantly contributed to the rise of the IBM. ${ }^{19}$ Nevertheless, the creation and execution of an IBM is still a delicate operation that requires substantial computational investment. ${ }^{20}$ Therefore, there is often a distance, if not a gap, between modelers and end users, which may have negative consequences. Even if some problems still exist, caused by the complexity of individual-based models, ${ }^{12}$ the recent progress in developing specialized platforms and tools has increased the accessibility of this approach to a broader range of scientists who may or may not have previous modeling experience. ${ }^{14}$

In this chapter we use a recently developed platform based on multiagent systems and specialized in the development of population dynamics models. ${ }^{20}$ This platform, called Mobidyc, is designed to make the end users true masters of their models without the assistance of computer experts. This new platform has been used to introduce an educational example that shows how IBM development can lead to new perspectives on our understanding of aquatic ecosystems structures and functions. First, Mobidyc has been used to build easily and without any hard-coding a model of the whole life cycle of the copepod Centropages abdominalis. We subsequently introduced (1) cannibalism, (2) predation, and (3) explicit spatial patterns to study their consequences on $C$. abdominalis at the population level. The results obtained here can be extended to other populations and/or organisms. In particular, within this platform the user can focus on model development and running experiments rather than hard-coding the model, which needs qualifications in computer programming that the biologist has not yet attained.

\subsection{Development of the Model}

\subsubsection{Main Characteristics of the Mobidyc Platform}

In the multiagent system (MAS) paradigm, agents perform their individual tasks with their own operational autonomy and reaction to their environment, but they influence the global behavior of the simulated system through local interactions. ${ }^{21}$ Mobidyc is an all-agents architecture that focuses more on what each agent does than on what it actually is. The advantage of this approach is that all the different elementary tasks that form the behavior of individuals can be clustered into a low number of classes of activities, e.g., locate, select, translate, compute, end, and workflow control. ${ }^{20}$ Mobidyc provides three kinds of agents: 


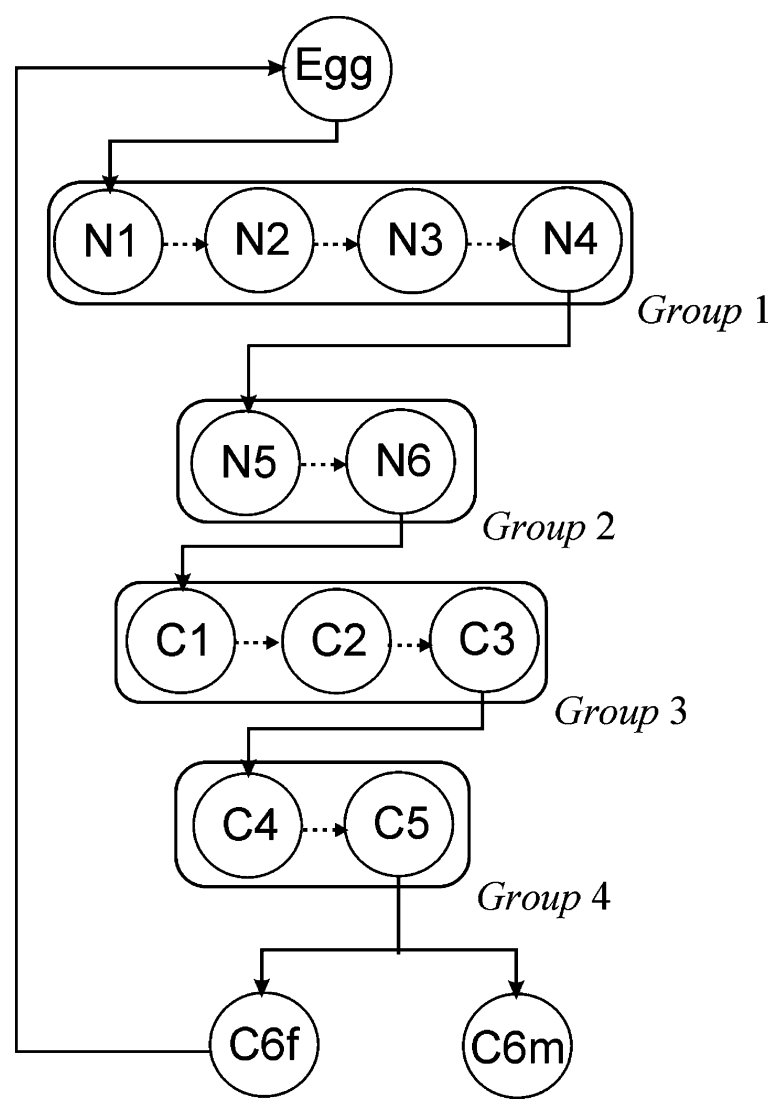

FIGURE 34.1 Schematic representation of a copepod life cycle with aggregation of post-embryonic stages into four groups: N1-N4, N5-N6, C1-C3, and C4-C5. Each stage is represented by a Mobidyc agent containing a dictionary of attributes and an ordered dictionary of tasks.

1. Animats that represent the typical individuals

2. Cells that represent a discretization of the space

3. Nonlocated agents that are optional and may provide general scenarios for all other agents or compute the results that the user wishes to save

\subsubsection{Life Cycle Representation}

For a cohort starting with eggs, and from an individual point of view, each individual egg has to follow the schematic template of Figure 34.1. To reach the adult stage (C6), an egg should pass successively through the six larval (naupliar) stages and the five juvenile (copepodite) stages. The success of this biological trajectory depends on the survival throughout all stages. Instead of using detailed representations of developmental stages, the life cycle of the copepod was simplified by aggregating post-embryonic developmental stages into four groups (Figure 34.1). The feeding mode of later developmental stages is omnivorous, and hence they were supposed to eat early stages (eggs to N4). So this life cycle representation aggregates similar stages from an ecological point of view (i.e., N1 to N4 accessible to predation), avoiding any disadvantages resulting from an over-aggregation of stages. ${ }^{11,22}$

\subsubsection{Model Architecture}

A basic animat corresponding to the classical individuals of IBMs already contains three attributes: age, location, and number. The last attribute is set to one to represent an individual; however, for other models 


\section{TABLE 34.1}

List of Attributes Used to Define the Life Cycle of the Copepod Centropages abdominalis

\begin{tabular}{lll}
\hline Attribute & \multicolumn{1}{c}{ Owner } & \multicolumn{1}{c}{ Definition } \\
\hline Age & All stages & Age (days) \\
Location & All stages & Position in the grid of cells \\
Number & All stages & Number of individuals per agent \\
Rand & All stages & Intermediate, used to assign a random real number between 0 and 1 \\
State & All stages & Intermediate, used to define the state of survival \\
pSurv & All stages & Probability of survival in the stage \\
Duration & Egg to C4-C5 & Stage duration \\
Weight & All stages & Body carbon weight ( $\mu$ g C) \\
stateSex & C4-C5 & Intermediate, used to define the type of sex in the stage C5 \\
pFemale & C4-C5 & Sex ratio of the population (proportion of females) \\
\hline
\end{tabular}

\section{TABLE 34.2}

Definition of the Tasks Used to Develop the Life Cycle of the Copepod Centropages abdominalis

\begin{tabular}{|c|c|c|c|}
\hline Agent Task & Definition & Type & Setting \\
\hline Grow older & $\begin{array}{l}\text { Compute the age of the } \\
\text { agent }\end{array}$ & Predefined & my_age:=my_age + simulator_timeStep \\
\hline StateSurvive & $\begin{array}{l}\text { Determine the state of the } \\
\text { agent for survival }\end{array}$ & $\begin{array}{l}\text { Predefined } \\
\text { (ModifyAttributes) }\end{array}$ & $\begin{array}{l}\text { my_rand }:=\text { Random_real }[0,1[ \\
\text { my_state }:=\text { my_pSurv }- \text { my_rand }\end{array}$ \\
\hline CondMortality & Conditional mortality & Predefined & if my_state $<0$ then I am dead \\
\hline TempDuration & $\begin{array}{l}\text { Effect of temperature on } \\
\text { the duration on the stage }\end{array}$ & $\begin{array}{l}\text { Predefined } \\
\text { (ModifyAttributes) }\end{array}$ & my_duration : = Random real [Dmi, Dmax[ \\
\hline Growth & $\begin{array}{l}\text { Effect of age on the } \\
\text { growth of weight for } \\
\text { groups of stages }\end{array}$ & $\begin{array}{l}\text { Predefined } \\
\text { (ModifyAttributes) }\end{array}$ & my_weight $:=\mathrm{W} 0 * \exp (\mathrm{g} * \mathrm{my}$ _age $)$ \\
\hline Hatching/Molting & $\begin{array}{l}\text { Transfer from one stage to } \\
\text { the next }\end{array}$ & $\begin{array}{l}\text { Predefined } \\
\text { (Metamorphosis) }\end{array}$ & If my_age $>$ my_duration \\
\hline DefineSex & $\begin{array}{l}\text { Define the sex of agent } \\
\text { after molting in the stage } \\
\text { C4-C5 }\end{array}$ & $\begin{array}{l}\text { Predefined } \\
\text { (ModifyAttributes) }\end{array}$ & $\begin{array}{l}\text { my_rand : = Random_real }[0,1[ \\
\text { my_stateSex }:=\text { my_pFemale }- \text { my_rand }\end{array}$ \\
\hline MoltingM/MoltingF & $\begin{array}{l}\text { Transfer from C4-C5 to } \\
\text { C6m/from } \mathrm{C} 4-\mathrm{C} 5 \text { to } \mathrm{C} 6 \mathrm{f}\end{array}$ & $\begin{array}{l}\text { Predefined } \\
\text { (Metamorphosis) }\end{array}$ & $\begin{array}{c}\text { If }((\text { my_stateSex }<0) \text { AND } \\
(\text { my_age }>\text { my_duration })) \\
/((\text { my_stateSex }>=0) \text { AND } \\
(\text { my_age }>\text { my_duration }))\end{array}$ \\
\hline Reproduction & $\begin{array}{l}\text { Reproduction of C6F into } \\
\text { eggs }\end{array}$ & $\begin{array}{l}\text { Predefined } \\
\text { (Reproduction) }\end{array}$ & $\begin{array}{l}\text { Number of offspring per individual equal to } \\
\text { my_fecund }\end{array}$ \\
\hline
\end{tabular}

Note: The predefined task ModifyAttributes is very useful for developing several models as the example shown here because it is designed to compute mathematical calculations involving agent attributes.

the number can be an integer for a group of identical individuals (i.e., clutch of eggs) or a real number to represent a concentration of a subpopulation. In our example, seven additional attributes are needed to complete the definition of the model without predation (Table 34.1). Souissi and Uye ${ }^{23}$ focused on a period of 5 months where zooplankton was largely dominated by the copepods $C$. abdominalis and Acartia omorii. ${ }^{24}$ For the same period the average values for temperature and chlorophyll concentrations were $12.25^{\circ} \mathrm{C}\left(\mathrm{SD}=2.73^{\circ} \mathrm{C}\right)$ and $4.50 \mu \mathrm{g} / \mathrm{l}(\mathrm{SD}=2.86 \mu \mathrm{g} / \mathrm{l})$, respectively. Hence, for the sake of simplicity, the simulations will be done using the constant values of $12^{\circ} \mathrm{C}$ and $5 \mu \mathrm{g} / \mathrm{l}$ for temperature and chlorophyll, respectively. The definition and the settings of the different tasks used for the first version of the model (without predation) are shown in Table 34.2.

Most agent behaviors require a computation of mathematical relations to update their attribute values. In Mobidyc, this is done through the task ModifyAttributes. An example of its use is demonstrated in Figure 34.2 with the setting of the copepod survival. 


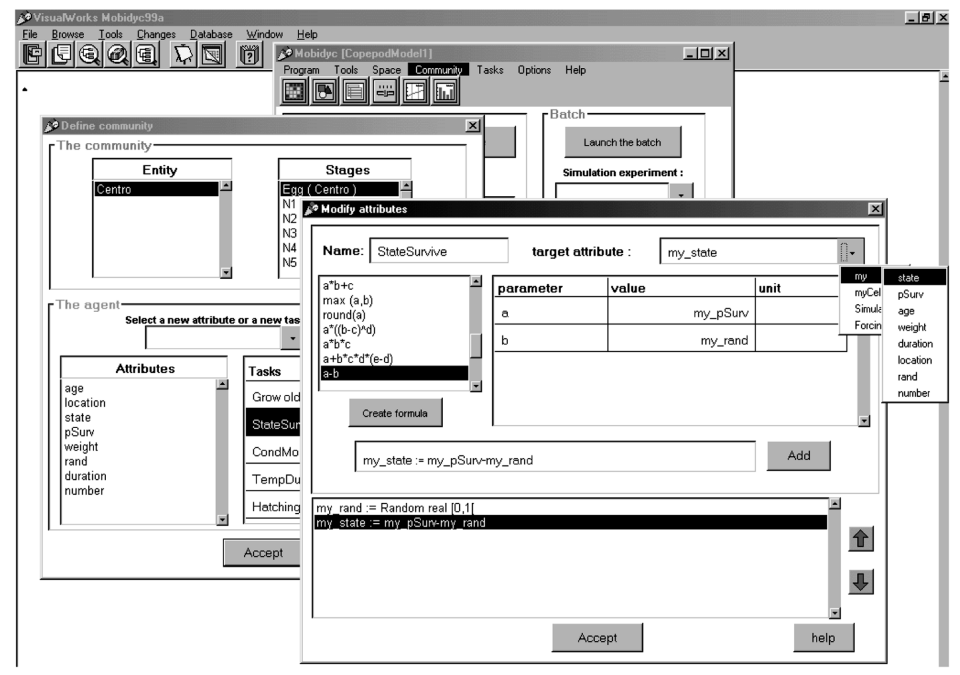

FIGURE 34.2 Snapshot of the task ModifyAttributes to define the state of survival in the egg stage. The mathematical expression can be chosen from the list on the left or can be created using a simple mathematical grammar syntax. A parameter value can be constant (fixed numerical value), an attribute value, or a function of an attribute value. For an animat, expressions can involve attributes of the running animat (i.e., my_pSurv), of its cell (myCell_attributeName), of one of the simulator characteristics (i.e., Simulator_timeStep), or of any nonlocated agent (i.e., Forcing_temp). One task using ModifyAttributes can contain a series of mathematical instructions. The window in the second plane is used to define the community from the principal menu of Mobidyc interface (the interface in the third plane and the VisualWorks environment in the background).

TABLE 34.3

Parameter Values Used in the Simulation

\begin{tabular}{lccccc}
\hline Stages & $\boldsymbol{D}$ (days) & $\boldsymbol{W}_{\text {min }}(\mu \mathbf{g} \boldsymbol{C}$ ind $)$ & $\boldsymbol{W}_{\max }(\mu \mathbf{g}$ C/ind $)$ & $\boldsymbol{g}(\mu \mathbf{g} \boldsymbol{C} / \boldsymbol{d})$ & $\boldsymbol{p}$ Surv \\
\hline Egg & 2.16 & 0.027 & 0.027 & 0 & 0.850 \\
N1-N4 & 8.65 & 0.015 & 0.077 & 0.19 & 0.900 \\
N5-N6 & 4.57 & 0.109 & 0.162 & 0.09 & 0.925 \\
C1-C3 & 8.22 & 0.233 & 0.882 & 0.16 & 0.925 \\
C4-C5 & 5.41 & 1.567 & 3.394 & 0.14 & 0.950 \\
C6m & & 4.187 & 5.117 & 0 & 0.975 \\
C6f & & 6.062 & 7.409 & 0 & 0.975 \\
\hline
\end{tabular}

34.2.3.1 Modeling Survival, Growth, and Molting of Individuals - The survival (or death) of any individual for a time step is given by the sign of the difference between its probability of survival (pSurv) and a random number drawn from an uniform distribution between 0 and 1 . For example, for a high value of survival (e.g., pSurv $=0.95$ ), the probability of drawing a random number greater than $p$ Surv is low; consequently, the individual has a greater chance of surviving than dying during the simulation. The individuals surviving in the stage should pass successively from one stage to another until they reach the adult stage. For constant conditions of food and temperature the probability of transfer from one stage to another is a simple function of age..$^{10}$ The individual variability of molting explains the shape of the probability distribution of molting rate at the population level. ${ }^{11}$ Using the empirical expressions proposed by Liang et al., ${ }^{25}$ we compute the stage duration $(D)$ and the weight $(W)$ of developmental stages (Table 34.3 ) for the considered temperature $\left(12^{\circ} \mathrm{C}\right)$. For aggregated stages (e.g., N1 to N4), the individual body mass varies between the value of the first developmental stage in the group $\left(W_{\min }\right)$ and the value of the last developmental stage in the group $\left(W_{\max }\right)$ (Table 34.3). We assume that the individuals newly recruited in the group grow exponentially with a constant growth rate $g$ (Table 34.3). For adult stages the individual weight interval $\left[W_{\min }-W_{\max }\right]$ is simply obtained by considering $10 \%$ of deviation around the computed value 
of weight. To introduce individual variability in stage duration a similar deviation (10\%) is also considered for the mean stage duration $(D)$. For these parameters ( $W$ of C6 and $D$ ) the value for each individual is taken randomly in the corresponding interval. The sex of individuals may be identified at stage C5.25 Because only adult stages are involved in the reproduction process, for the sake of simplicity, the sex of individuals is only separated in the adult stage with a sex-ratio 1:1. In stage C4-C5 two tasks of metamorphosis are defined, one corresponding to the molting into males (MoltingM) and the other task represents the molting into the female stage (MoltingF).

34.2.3.2 Reproduction - The empirical expression developed by Liang et al. ${ }^{26}$ for C. abdominalis fecundity is used. For nonlimiting food conditions and at temperature of $12^{\circ} \mathrm{C}$, the daily egg production rate computed with Liang's model equals $85 \mathrm{eggs} /$ female. Consequently, during one time step of simulation ( 0.5 days) the number of eggs produced by one female is taken randomly between 38 and 47 , which represents $10 \%$ of dispersion.

34.2.3.3 Predation - The expressions given here are used for representing both cannibalism of older developmental stages and for predation by an external predator that we will introduce later. In all cases the vulnerable individuals belong to early developmental stages: from eggs to N4.

34.2.3.3.1 Effect of Body Weight and Temperature on the Ingestion Rate. The general allometric relationship between the maximal specific ingestion rate $\left(I_{\max }:\right.$ day $\left.^{-1}\right)$ and the body mass $(\mu \mathrm{g} C)$ given by Moloney and Field ${ }^{27}$ was used:

$$
I_{\max }=0.56 W^{-0.25}
$$

The effect of temperature on ingestion rate is introduced by assuming an exponential effect with $Q_{10}$ set to 3 , a common value for zooplankton equal to $3 .^{23}$ The combination of the effects of body mass and temperature leads to the following expression:

$$
I_{(W, T)}=\Delta t \times I_{\max } \cdot W \cdot\left(e^{0.1 \log \left(Q_{10}\right)\left(T-T_{r}\right)}\right)
$$

where $I_{(W, T)}$ is the maximal ingestion $\left(\mu \mathrm{g} C \cdot i n d^{-1}\right)$ during a simulation time step $(\Delta t=0.5 d), W$ is the individual body mass $\left(\mu \mathrm{g} C \cdot\right.$ ind $\left.^{-1}\right)$, and $T_{r}$ is the reference temperature $\left(20^{\circ} \mathrm{C}\right)$.

34.2.3.3.2 The Predation Task. We have to build a user-defined task that we have chosen to call PredateOneStage by using the proper primitives (Figure 34.3). The predator should first locate the prey agents according to its spatial perception. In our example we limit the predator perception to the cell where it is located, so the starting primitive is MyCell. But a more general primitive, called MyNeighborhood, returns the adjacent cells of the running animat or cell according to a radius, and can also be used as a starting primitive.

In a second step, the predator should select the prey. This action is represented by two successive primitives FromCellToAnimat giving all animats on the cell and SelectOnName giving only the reduced list of stages accessible to predation. Then the predator agent eats the preys randomly until its satiety is reached or when the list of prey is empty. The primitive ModifyAttributes computes the stocking of ingested matter with an efficiency of $70 \%$. This quantity is stocked on a new attribute called ing.

We can now add this new task to any developmental stage or other new entity. For example, for C6 stages we need only to compute the maximal ingestion using the mathematical expression of ModifyAttributes and then to adequately parameterize the predation task. We will show in Section 34.3.4 how the same task of predation can be parameterized differently for another predator.

\subsection{Results}

\subsubsection{Simulation of the Mortality of a Single Stage: Role of the Demographic Noise}

Several studies have focused on the effects of demographic stochasticity on the extinction risk of populations. ${ }^{28}$ Kendall and Fox ${ }^{29}$ suggest that demographic variation should be interpreted as individual 


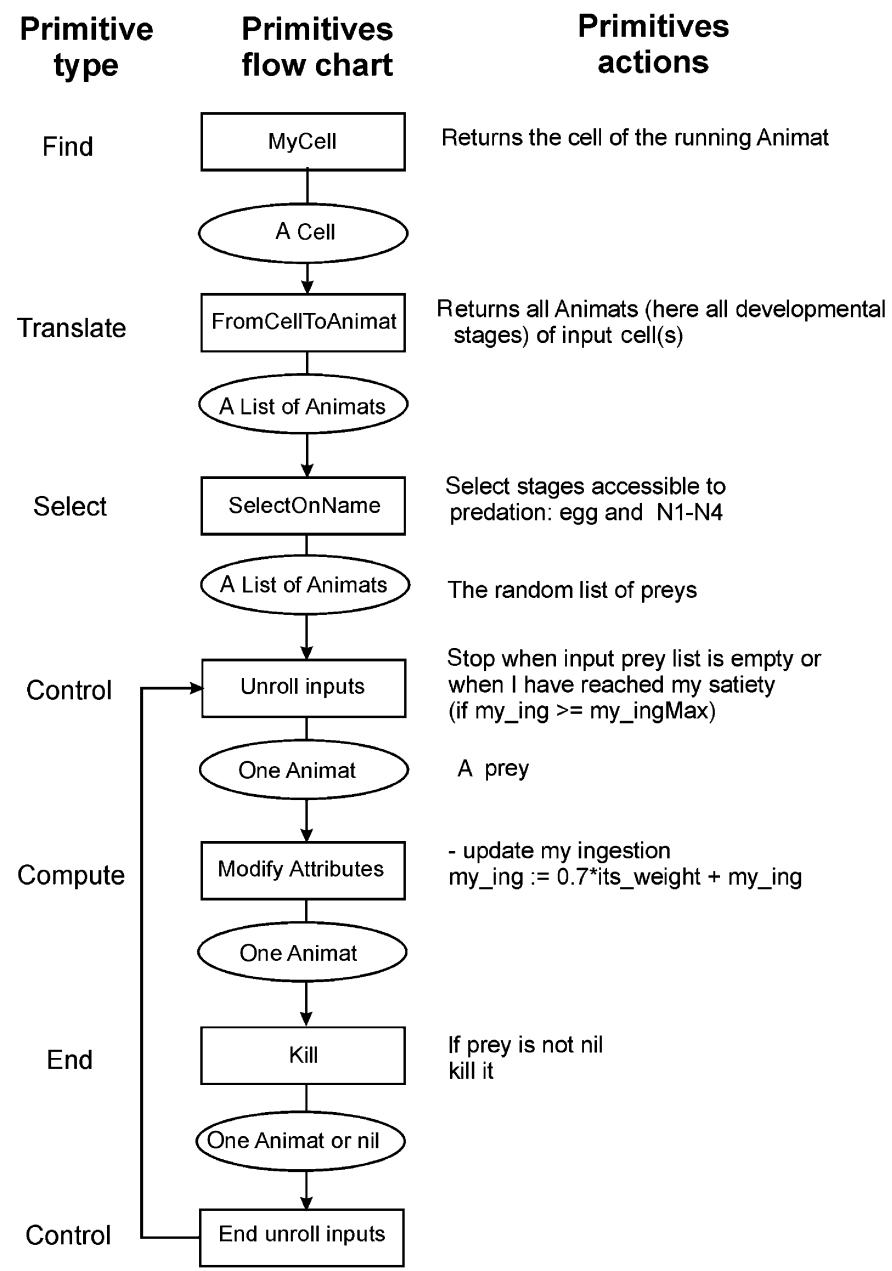

FIGURE 34.3 An example of building a task with primitives, here a task of predation of omnivorous stages (C6m and C6f) on early developmental stages (eggs, N1-N4). Seven primitives (represented with boxes) corresponding to six types are strung out to build this task. The output arguments of each primitive (represented with ellipses) represent the input argument of the next primitive.

variation in demographic traits, rather than as sampling error. One individual may do well and reproduce, a predator may eat another, while another may fail to reproduce because it did not find any mate. All these random variations are ignored when we consider the average birth or death rates of a population. ${ }^{30,31}$ To illustrate the role of demographic noise the basic example of a single stage is presented. The probability of survival (pSurv) varied from 0.975 to 0.800 with 0.025 increments. For each $p$ Surv value 20 runs were realized, to reach a significant representation of the variability between runs. Figure 34.4A shows the results of these simulations for the four selected values of pSurv: 0.975, 0.925, 0.875, and 0.825. For fairly large numbers of individuals, this probabilistic interpretation of $p$ Surv is similar to a deterministic model (Figure 34.4). However, if only a small number of individuals remain (e.g., fewer than 30 individuals) significant deviations from the deterministic mean may occur.

Each set of 20 simulations is used to estimate the constant mortality rate $\left(z\right.$, day $\left.{ }^{-1}\right)$ by fitting the exponential model $\left(N_{t}=N_{0} e^{-z t}\right)$. The different fits for each set of simulations are shown in Figure 34.4A with continuous lines. The effects of varying time interval windows used to fit the model are negligible; hence the average value of $z$ is used to establish a linear relationship between pSurv and $z$ (Figure 34.4B). The importance of taking the individual probability of survival is emphasized, especially when the number of individuals is low. 


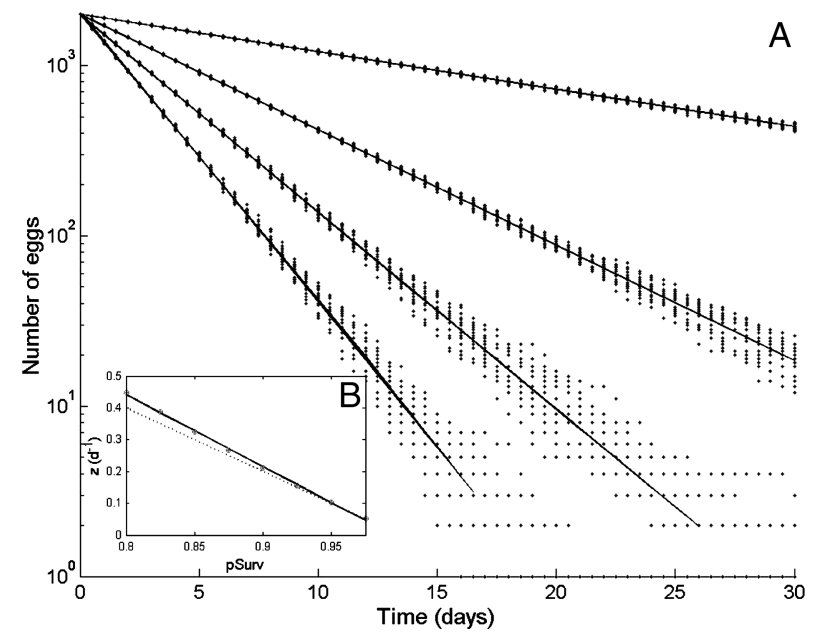

FIGURE 34.4 (A) Simulations of the decrease of individuals in a single stage with four different values of probability of survival $(0.975,0.925,0.875$, and 0.825$)$. The symbols represent the simulated points for 20 repetitions and continuous lines are the fit of Equation 34.4 for several time intervals (see text for more details). (B) The continuous line represents the linear regression $p$ Surv used in the model and the fitted value of $\left(z=-2.269 p S u r v+2.257 ; r^{2}=0.999\right)$. The discontinuous line represents the theoretical line of equation $z=2(1-p$ Surv $)$.

\subsubsection{Simulation without Predation}

Now consider a local population of the copepod C. abdominalis, all simulations starting with four females and four males. The model correctly simulates the succession of the developmental stages with respect to their stage durations and other demographic parameters such as reproduction and mortality (Figure 34.5). The stochastic representation of the stage survivals (Table 34.2) shows the visible differences between the five runs realized with the same set of parameters (Figure 34.5). For longer simulation durations the population should increase exponentially, which is a general property of stagestructured populations simulated under nonlimited conditions.

\subsubsection{Effect of Cannibalism and Spatial Representation}

As a first step, the predation task PredateOneStage is activated for adult stages (i.e., C6m and C6f) without modifying the other parameters of the model. With no spatial representation (i.e., all individuals in the same cell), all runs resulted in the extinction of the population. There is no viability for the Centropages population under these conditions. This occurred because without spatial representation, the encounter between prey and predators is maximal as there is no refuge for the prey.

To study the effects of spatial representation we consider a grid of hexagonal cells (each cell has six neighbors) and add the predefined task Move for all developmental stages except eggs. This task can be parameterized to reproduce a random walk according to a radius of action, given in number of cells, or following a gradient of an attribute of the cell. For example, if cells represent a resource, agents can move following an increasing (or decreasing) gradient of the resource. Here, all agents move randomly with a radius of action of one cell. Figure 34.6 shows the results of simulation of the population (five runs) for a grid of $5 \times 5$ cells. The introduction of the spatial representation increased the time duration of the simulation before the extinction of the population. There was no recruitment for the second generation for all runs (Figure 34.6). By increasing the spatial grid to $10 \times 10$ cells, the viability of the population becomes possible (Figure 34.7). However, two runs of five produced extinction of the population.

\subsubsection{Effect of Predation on the Spatiotemporal Dynamics of the Population}

The early developmental stages of copepods are also the prey of many other zooplankters, particularly fish larvae. ${ }^{32}$ These visual predators can locate prey patches or individual prey according to their visual 

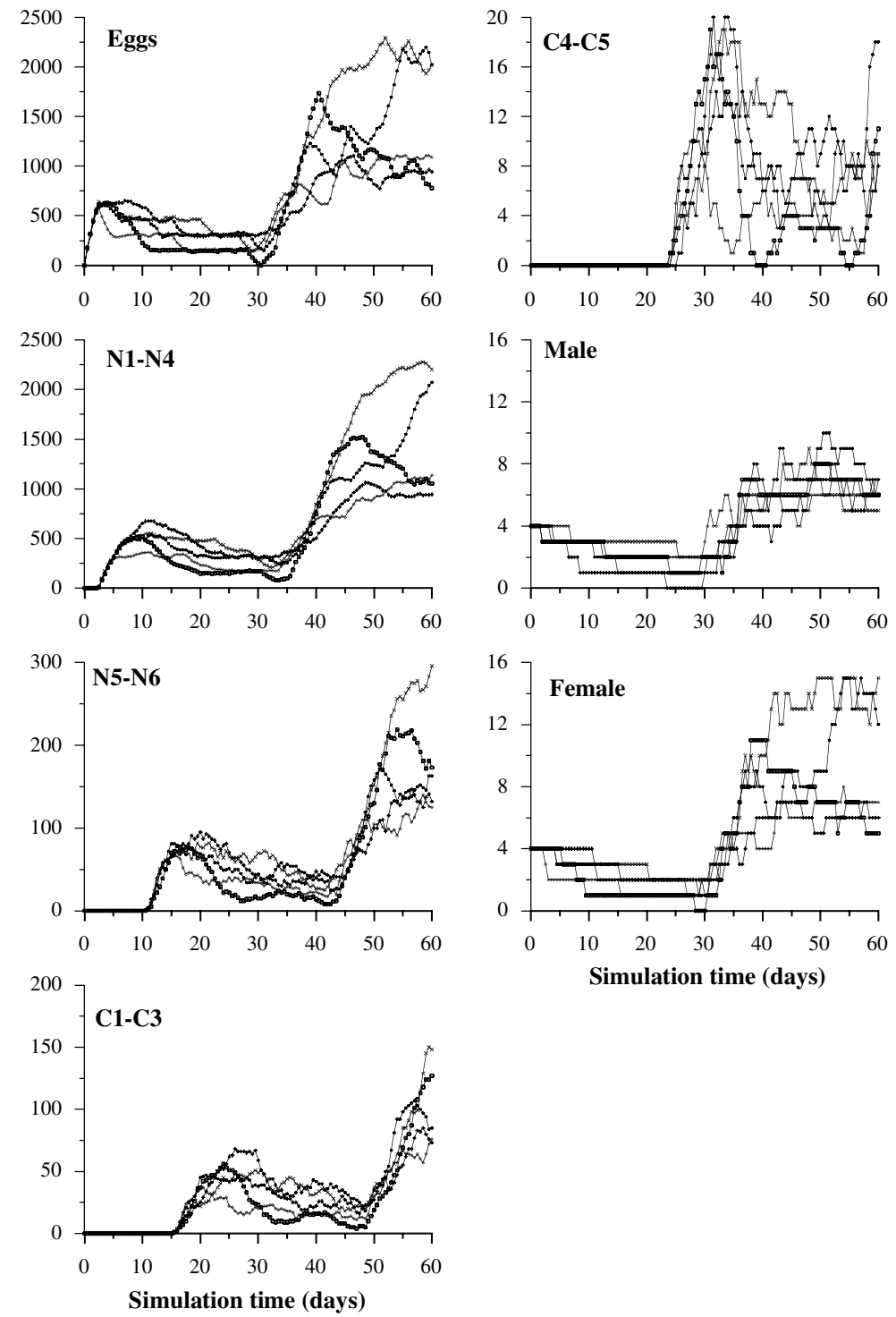

Simulation time (days)

FIGURE 34.5 Simulation of the development of the population of C. abdominalis during 2 months under constant conditions of food $\left(5 \mu \mathrm{g}\right.$ chlorophyll/l) and temperature $\left(12^{\circ} \mathrm{C}\right)$. Five runs (represented with different symbols) are realized with the same initial conditions of a mixture of eight adults with a sex-ratio $1: 1$.

field before attacking. ${ }^{33}$ In this simulation an additional predator (i.e., small fish larvae) eating only the first developmental stages is added. Figure 34.8A shows the initial conditions with four males (gray triangles), four females (black triangles), and six predators (squares). Each predator had only one developmental stage and is able to move in its search area (Figure 34.8A) to the cell containing the highest density of prey. The user-defined task PredateOneStage is now added to the new predator (agent) and parameterized as previously done for adult stages. The maximal ingestion per predator and per day (Imax) was set to the arbitrary value of $1 \mu \mathrm{gC}$. In order to compute the densities of prey, a simple task was assembled and added to each cell. The representation of this agent (predator) and the cells is detailed according to the syntax (macrolanguage) proposed by Houssin et al. ${ }^{34}$ in the appendix to this chapter.

Figure 34.8 shows the spatiotemporal evolution of the system. The spatial heterogeneity of prey distribution can be explained by the random walk of copepod females (with a one-cell range). Here, the order of the tasks of adult females is crucial and may modify the results of the simulation. We used the 

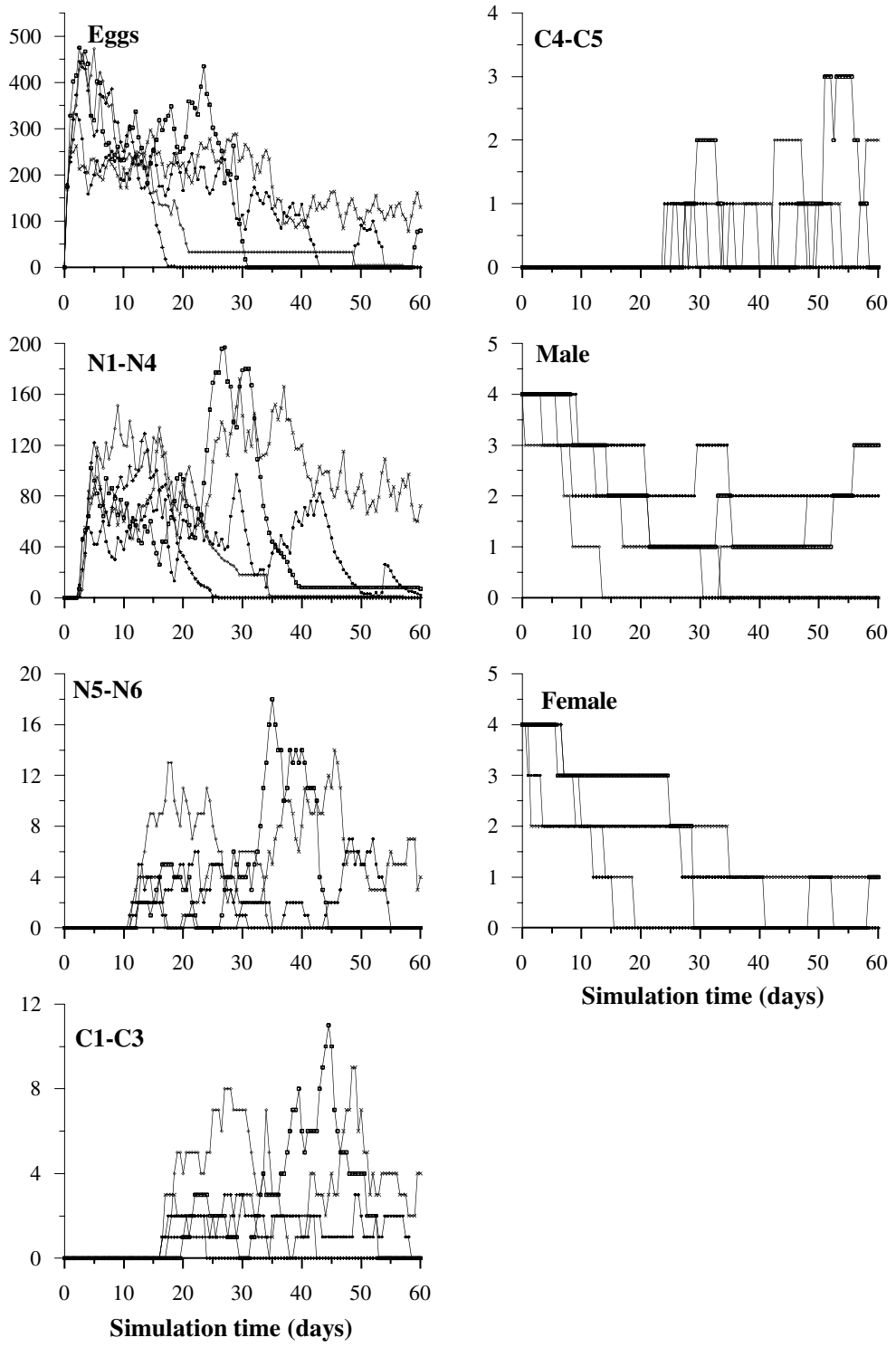

FIGURE 34.6 Simulation of the development of $C$. abdominalis over 2 months. Space is represented by a grid of $5 \times 5$ hexagonal cells. All postembryonic developmental stages move with a radius $=1$ cell. The predation task shown in Figure 34.3 was activated for the stage C6. The other parameters of the simulation are identical to those of the runs obtained in Figure 34.5.

following task order, Move $\rightarrow$ PredateOneStage $\rightarrow$ Reproduction, which gives an additional chance to the laid eggs in the parental cell to escape from parental predation. Figure 34.8B shows an isolated local maximum (low area of the grid) of prey density after 5 days of simulation. This maximum corresponds to the reproduction of the nearest female (Figure 34.8B). This "patch" of prey is located in the search area of two predators that moved simultaneously to the same cell. The model is defined in a sequential way so the first predator, taken randomly, will modify the state of the system (i.e., number of prey). With such a simple representation of the feeding behavior of the predators, a school of predators is obtained after 8.5 days of simulation. Figure $34.8 \mathrm{C}$ shows an intersection of search areas of all predators composed by three cells and containing one female. All predators locate the same patch and move to the same cell (Figure 34.8D). The predators with simple deterministic behavior stay within the school 

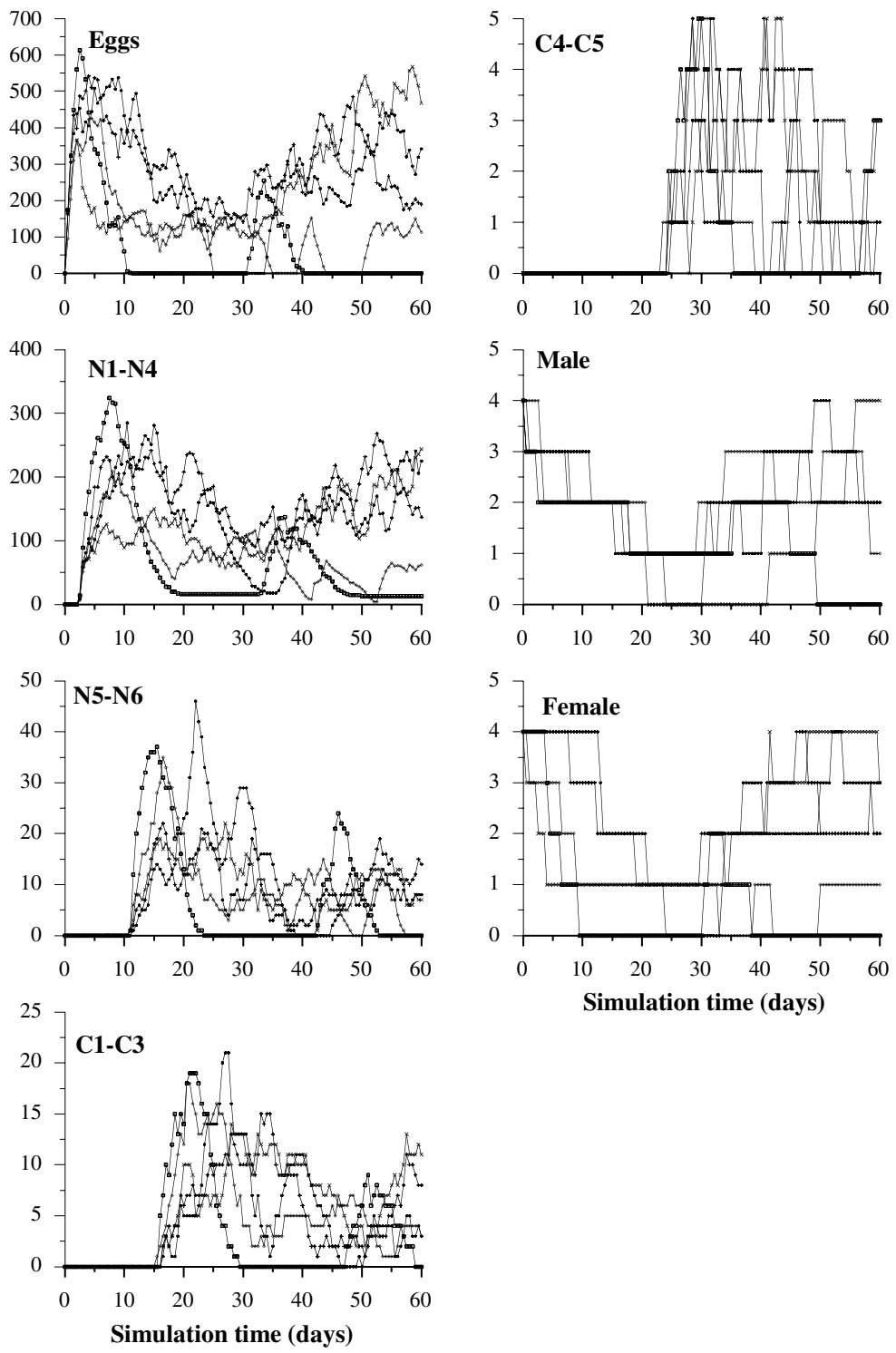

FIGURE 34.7 Simulation of the development of C. abdominalis in a grid of $10 \times 10$ hexagonal cells. The other conditions and model parameters are identical to those of Figure 34.6.

until 13 days of simulation (Figure 34.8E). The school then locates itself to a poorer area and the patch of prey outside their search area. The predators have no advantage to stay in the school because the prey density does not sustain their bioenergetic demand and then the school is separated (Figure 34.8F). All these behavioral and spatial patterns result from the interaction between individuals and can be regarded as the emerging properties of the system.

\subsection{Discussion}

Because IBM-related approaches are sometimes nonconvergent, noncompatible, and/or nonaccessible to a wide range of computer- and noncomputer-oriented scientists, we stress here the need to agree on a scientifically sound and common framework. This may speed and facilitate direct exchanges among 

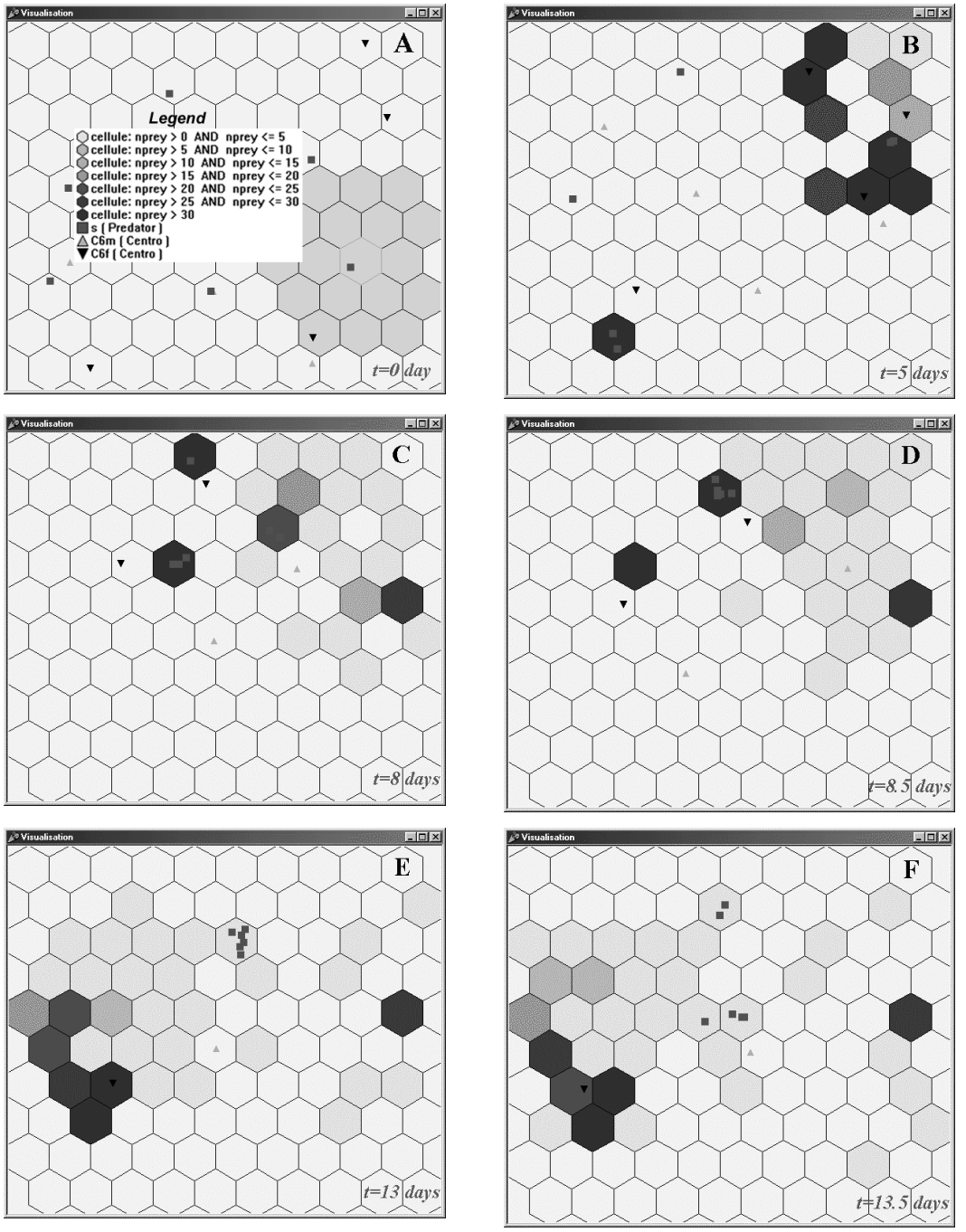

FIGURE 34.8 Effect of predation on the spatiotemporal dynamics of the development of the population of C. abdominalis. (A) Initial condition of the simulation, cells count the vulnerable stages to predation (eggs and N1-N4), which are then represented with a color scale. The legend shows only stages exerting a predation C6m (gray triangle), C6f (black triangle), and the predator (square). The gray cells show the search area of one predator corresponding to the radius of action = 2 cells. (B) Spatial structure after 5 days of simulation. (C, D) Two successive time steps representing the formation of a school of predators. (E, F) Two time steps representing the separation of the school of predators.

IBM-oriented scientists. Particularly, this goal may be achieved only via establishment of a common procedure requesting clear definition of the link between IBMs, theory, common methodology, tools, and languages, as well as clarification of the connections between IBMs and population dynamics.

\subsubsection{Toward an Improvement of Individual-Based Models}

\subsubsection{A Common Methodology for IBMs}

As the populations are represented by a collection of interacting individuals and not by continuous densities, the development of IBMs should change our way of modeling biological systems. ${ }^{35,36}$ This new way of modeling, referred to as the "bottom-up" approach, presents a great potential for challenging theoretical and practical ecological studies. ${ }^{15,19}$ However, a recent review covering the last decade ${ }^{18}$ clearly shows that the potential offered by this approach is still far from being fully exploited. Additional 
experiments with IBMs should be conducted to try to relate them more directly to theory. Levin and Durret $^{37}$ have argued that phenomenological approaches are deficient in that they lack attention to underlying processes, whereas IBMs may obscure the essential interactions in a sea of details. They nevertheless recognize the advantages of IBMs and suggest that the gap be bridged between the mathematical formalism of classical approaches and the detail of IBMs. On the other hand, recent papers based on simple mathematical models of population dynamics have suggested the use of stochastic IBM approaches, which are more appropriate for considering environmental variability and individual behavior. ${ }^{9}$ In general, IBMs are used because a fundamental significance of individual variability is suspected, i.e., significance with respect to persistence and other dynamic properties (resilience, resistance) of the population. ${ }^{12}$ However, in their present state, IBMs have several drawbacks and should be developed according to a common methodology. Some recent studies have focused on comparative studies between classical and individual-based models. Wilson ${ }^{38}$ showed that the IBM representation of a spatially distributed predator-prey population leads to strong spatial structuring in contrast to predictions from its representative analytical formulation. Sumpter and Broomhead ${ }^{39}$ approximate the emerging properties of an IBM at the population level by a logistic equation. They further demonstrate how this approximation is obtained mathematically and how the parameters of the exponential logistic equation can be written in terms of the parameters of the individual-based model. Recently, Berec ${ }^{40}$ showed that a class of spatially explicit IBMs could be analyzed mathematically by relating them to partial differential equations. In these examples the IBM formulation is close to the analytical model at the population level. From these basic examples, it can be seen that the outcome of IBMs can and cannot be comparable to the results provided by more standard modeling approaches. This is an extremely strong argument to demonstrate the ability of IBMs to provide new insights into a priori known results regarding patterns and processes in both space and time.

The development and use of IBMs is continuously increasing, and the development of a new framework for their analysis and comparison is recommended. Only a few studies have proposed such techniques capable of capturing generalities to gain insight beyond a specific simulation model..$^{13,41}$ Recently, Railsback ${ }^{17}$ proposed using the main concepts from a new research field of complex adaptive systems (CAS) as a theoretical foundation for IBMs. CAS study the emergence of complex behaviors even in systems based on relatively simple interactions between few individuals. The proposed framework converges toward Grimm's recommendations proposing that IBM modelers concentrate more on the process of modeling itself rather than merely on the entities that are modeled. ${ }^{18}$ All these recent papers have aimed at improving the great potential of IBMs in contributing significantly to basic and applied ecology recognize the necessity of improving computer implementation and reproducibility of models.

34.4.1.2 Common Tools for IBMs - Unfortunately, most published IBMs are not readily available to the whole scientific community and still look like "black boxes" of bygone years. Although Grimm ${ }^{18}$ presented a review of IBMs published in the last decade on the basis of 50 papers, he simply classified these models according to a set of criteria (see his table 1). One fundamental difficulty in the evaluation and comparison of IBMs in the literature arises from the absence of any theoretical formalism, such as differential equations, where one can express, conserve, and compare one model to another, or to export it to another modeling tool. This problem of readability, which was briefly raised by Judson, ${ }^{19}$ amplifies the suspicion with which the results of an individual-based model may be viewed. On the other hand, the number of platforms and tools dedicated to developing object-oriented modeling has increased although their accessibility to noncomputer scientists remains limited. A good example of a multiagent software platform for the simulation of complex adaptive systems is the Swarm software. ${ }^{42}$ Lorek and Sonnenschein ${ }^{14}$ revised these tools and focused on the conception of a modeling tool (WESP-TOOL) more accessible to end users in developing and analyzing IBMs for metapopulations. This imposed a better separation of the components of the model from those of the platform, and the result was more reliable as the platform controls more components involved in the execution of the model. These efforts try to clarify the "black box" or the model in simulators, but even if scientists develop most of these models they often remain inaccessible to experts in population dynamics. These systems require ecologists to develop some computer programming skills, although the software provided makes the process of programming easier. ${ }^{43}$ 
In the specific framework of Mobidyc, we have focused on the concept of constructing several IBMs with increasing levels of complexity and using them to study different questions. All these steps were developed without hard coding. Moreover, the use of primitives allowed for the decomposition of each task into some elementary tasks. With this approach, the end-user modeler can easily control all steps of model implementation. Consequently, he or she can test easily several algorithms and/or parameterizations involved in the model. This concept is fundamentally different from building a unique and complete model, which may be more realistic but too complex to allow easy validation of all the steps used to build it. In such a situation it is difficult to compare this model with others because the code sources or the architecture are not easily accessible. On the contrary, the examples developed here with Mobidyc can be made by any end user after familiarization with the Mobidyc architecture. This platform is fully adapted to end users and should be enriched and strengthened in the future by incorporating feedback from users, for example, adding new primitives and enriching the library of examples. The main objective is to dissociate IBMs from the simulator carrying out their execution.

34.4.1.3 Common Languages and Common Descriptions for IBMs - Up until now, the biggest weakness of modeling tools is that there is no link between the natural language in which the researcher describes the model and the actual programming language in which this model is written. Mamedov and Udalov ${ }^{43}$ proposed the CENOCON software to provide a means to run conceptual ecological models where programming is not needed at all. Even though this software takes a text file with descriptions of organisms and space, giving more flexibility to the running of IBMs, the main structure of the simulator and the proposed rules of interactions between species are still imposed by the authors. For example, a user should understand the whole complex mechanisms behind this simulator (see their fig. 1). This situation may slow the process of standardization of IBMs as a useful tool for ecological studies. Lorek and Sonnenschein ${ }^{14}$ proposed a WESP-DL specification language, which is completely defined and stable. However, this macrolanguage requires a minimum of syntax to structure the program. Alternatively, the macrocommands used here with the primitive ModifyAttributes (see Figure 34.2) provide a closer description because the mathematical expressions are associated with the agent's attributes. In both cases the descriptive language is nevertheless not separated from the platform or the simulator. The use of component programming (through primitives in this example) may facilitate the design of a domain-specific language in which these models could be written independently of the platform. An example shown in Appendix 34.A was inspired by Houssin et al. ${ }^{34}$ showing us the expert language used to describe a predator searching for prey and cell counting for those prey. Using primitives improves task description (i.e., example of Figure 34.3) and offers a promising framework for developing macrolanguages of model description, which are closer to expert languages (see Appendix 34.A). The aim of this framework is to make model development independent of platforms. The model can be built interactively using the platform and then translated to this language. Furthermore, this textual language can be compiled with any adapted compiler without needing an interface, gaining in execution and performance. ${ }^{34}$

\subsubsection{IBMs and Population Dynamics of Zooplankton}

With the exception of a few examples of object-oriented models developed for zooplankton species ${ }^{44-46}$ representing "true IBMs," the classical state variable approach has been common practice in the modeling of zooplankton populations. ${ }^{47,48}$ Moreover, the term IBM is sometimes used whereas the average values are modeled. ${ }^{2,49}$ The later examples cannot be considered "true IBMs" according to the previously given definition in this chapter because resources used by individuals typically are not explicit. As a matter of fact, these models assume that individuals are born, produce offspring, and die practically at the same moment, as well as assuming that all individuals are identical. ${ }^{50}$ The introduction of physical variability and advection can produce different spatial and temporal patterns. ${ }^{51}$ However, the same equations and parameterization are used for all individuals. The only possible difference between individuals comes from the set of environmental factors generated by physical models. With such coupling in physical-biological models, physical forcing drives most of the biological patterns. 
Uchmański ${ }^{50}$ considered that the use of IBMs only where the description of individual life cycles includes stochastic elements that allow us to explore the importance of individual variation as opposed to population dynamics. The behavioral interactions between individuals represented in IBMs can also be responsible for global population dynamics. ${ }^{39}$

In this chapter illustrative applications are developed to show the potential of IBMs. The simulations shown here confirm the earlier conclusions on their role for both small-sized populations and local scales. ${ }^{41}$ Mooij and Boersma ${ }^{46}$ showed that most demographic parameters of Daphnia populations simulated using an object-oriented model varied as a function of the number of modeled individuals until a threshold value was reached (around 100 individuals) above which the simulated parameters remained constant. In our first example, the variation in the probability of survival in a single stage showed an increase of dispersion between runs for low numbers of eggs (Figure 34.5). This is fully consistent with our above-stated results. The examples developed in this chapter are specifically adapted to local populations, which encompass most ecological situations in aquatic ecology, at least in zooplankton ecology. ${ }^{52,53}$ The introduction of both individual behavior, even though simply represented, and spatial representation, pointed out the need for careful consideration of the links between spatial scales and their consequences on population dynamics. To introduce the potential effect of spatial dispersion (e.g., due to diffusion or advection or any other processes) we considered a large grid of $50 \times 50$ cells. Figure 34.9 shows the effects of initial density of adults and the introduction of advection on the temporal evolution of eggs. Without advection, each female produced very local populations and consequently fully controlled the development of its production. This situation leads to a stable global population with a low abundance (Figure 34.9A, C, and E). On the other hand, the introduction of dispersion of eggs and N1 to N4 increased the size of the population (Figure 34.9B, D, and F). One must also note here the increase in variability between runs for the same initial conditions. In this way, any extrapolation conducted on both in situ biotic and abiotic processes and based, for example, on averaging or least squares procedures, is very suspicious if not irrelevant. It is thus of major interest to take into account possible interactions between individuals, local populations, and physical forcing. Here again spatially explicit IBMs can be helpful to study these between-scale transfers as well as the interaction between physical and biological processes.

Recently, Seuront and Lagadeuc ${ }^{54}$ continuously sampled the population of the calanoid copepod Temora longicornis, and assessed the high heterogeneity observed using multiscaling analysis techniques. The observed patterns of spatial distributions of copepods ${ }^{55}$ at several scales gave new direction to the development of new sampling techniques adapted to the small scales characterizing plankton development. By taking into account the possible complex interactions between external (turbulence, advection, food patchiness) and endogenous (feeding behavior, vertical migrations) mechanisms leading to patchy properties of plankton distribution, ${ }^{52,53}$ IBMs will also be useful for improving studies concerned with small-scale processes. Other sampling techniques (plankton nets) give estimations for seasonal (or larger spatial scales) patterns. However, small-scale variability is excluded, increasing the difficulties in interpreting the results when either models of population dynamics or inverse techniques are used. Souissi and $\mathrm{Uye}^{23}$ developed a model representing the predator-prey interactions involving several developmental stages of the copepods, C. abdominalis and Acartia omorii. An age-within-stage model based on differential equations and the previously published parameterization of demographic processes was used. ${ }^{10,11,48}$ The model simulated interesting patterns of the temporal evolution of the predation rate..$^{23}$ The different numerical simulations confirmed the role of predation and cannibalism in controlling these copepod populations, as argued empirically by Uye and Liang. ${ }^{24}$ The modeling exercise allowed some biases in sampling strategies to be revealed, leading to an underestimation of early developmental stages. The data used in Souissi and Uye ${ }^{23}$ and published earlier in Liang et al. ${ }^{25}$ are not adapted to be used for validation of IBMs such as the models developed here. However, it is interesting to mention that models without spatial dimension (0D) give one deterministic run for a fixed combination of the number of parameters. Stage-structured population models, even those based on mathematical representations, generally ordinary differential equations (ODEs), still remain difficult to validate. ${ }^{56}$ In addition, these OD models assume a homogeneous distribution of copepods. In other words, irrespective of volume, these models represent processes in the same way (1 liter, 1 cubic meter, other volume). Most other cases coupling copepod development with physical models have led to one-, two-, or three-dimensional 

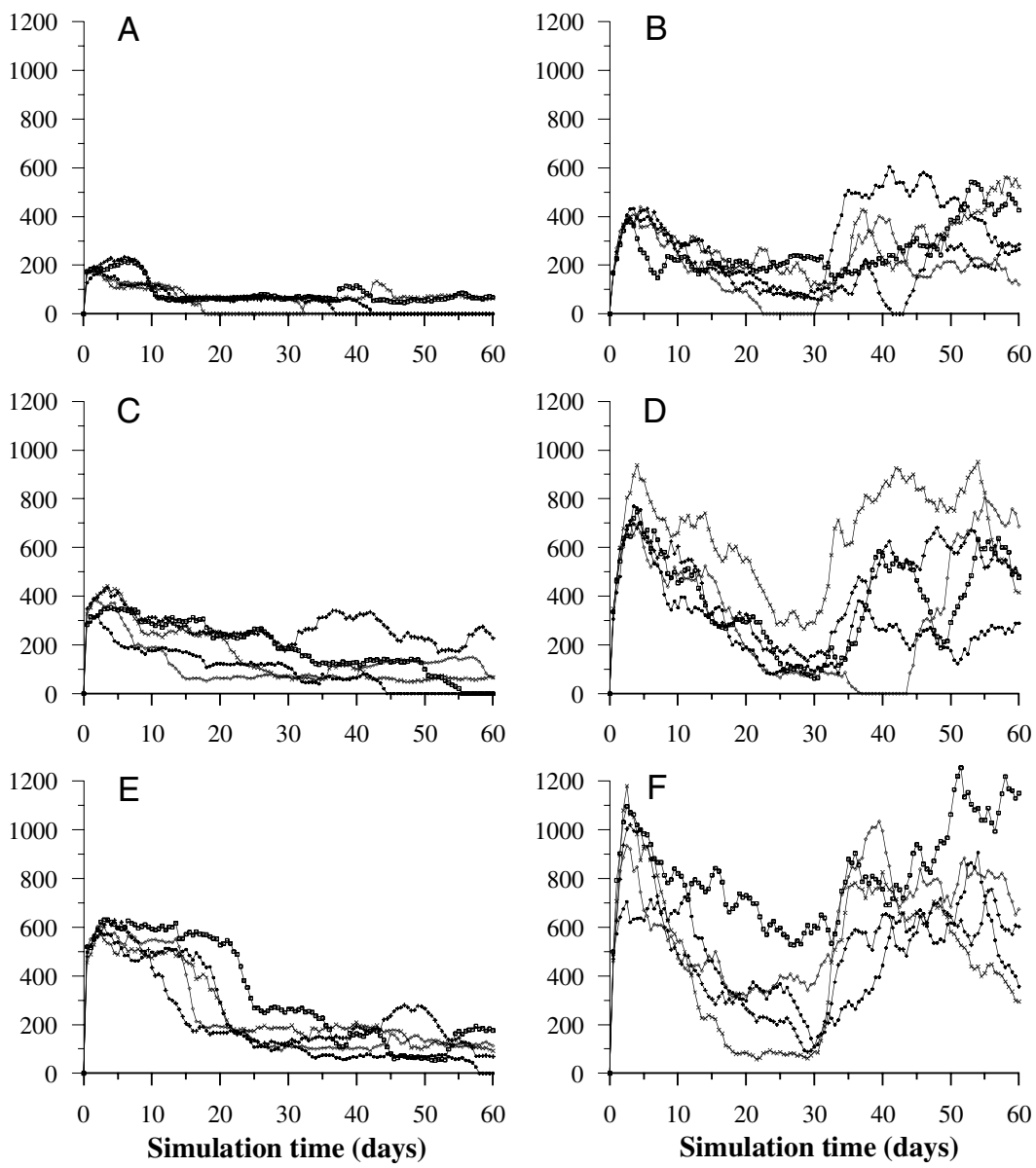

FIGURE 34.9 Simulation of the effects of the initial density of predators and the advection represented by a nondirectional random walk on the time evolution of eggs in a large grid of $50 \times 50$ hexagonal cells. The other conditions and model parameters are identical to those of Figure 34.5 to Figure 34.7. The figures on the left (A, C, E) correspond to simulation without advection; the produced eggs stay in the cell and the stage N1-N4 move randomly with a radius $=1$ cell. The figures on the right $(\mathrm{B}, \mathrm{D}, \mathrm{F})$ represent a dispersion of prey (eggs and $\mathrm{N} 1-\mathrm{N} 4)$ introduced by considering a random walk with a maximal radius $=3$ cells. The initial conditions were modified: 4 males and 4 females (A, B), 8 males and 8 females (C, D), and 12 males and 12 females (E, F).

simulations where the representation of copepods was very simple..$^{51,57,58}$ In most simulations, copepods follow the hydrodynamic fields without expressing possible feedback on physical processes.

Another major advantage of IBMs based on object-oriented modeling is the possibility of synchronous (pseudo-parallelism) representation; for example if a prey is met by two predators only one predator can capture it. This modeling approach considers a population as a consequence of individual interactions, so this advantage should be explored to study the emerging properties using several behavioral scenarios. In particular, the framework of complex adaptive systems proposed by Railsback ${ }^{17}$ seems to be well adapted to develop IBMs for copepod populations.

\subsection{Conclusion}

We suggest at this point that the development of individual-based approaches in aquatic ecology should be regarded as the basis of our future understanding of patterns and processes observed in the ocean. Generally speaking, in aquatic ecology an increasingly synoptic viewpoint should also be established 
taking into account the rapidly developing multiscale technology (e.g., References 59 and 60). More specifically, in plankton ecology the combination of both endogenous (physiology and behavior) and exogenous (e.g., turbulence) processes via IBMs will undoubtedly ensure the reconciliation of the observed discrepancies between experimental or field data and the more classical standard modeling approaches.

\section{Appendix 34.A}

Expert language proposed to describe the predator and the cells used in the simulations of Figure 34.8. This macrolanguage used to describe the models developed with Mobidyc is closer to an expert language. It is inspired by the example developed by Houssin et al. ${ }^{34}$ Reserved words or system-generated locutions are in italics. Comments (both user-defined or system-generated) are delimited with \{\} .

\section{\{ Predator definition \}}

\section{[ Entity ]}

Name : Predator ;

\section{[ Stages ]}

$\mathrm{s}$

\section{[ Attributes ]}

location, age, number ; $\quad$ [default attributes

$\operatorname{Imax}=1 ; \quad$ \{maximal ingestion rate

Ing $=0 ; \quad$ \{stock of ingested preys

[ Tasks ]

Grow older

$$
\left\{m y \_a g e:=m y \_a g e+\text { Simulator_timeStep }\right\}
$$

Move

\{predefined: GrowOlder\}

\{Reach a cell according to the following parameters and options: include the initial cell in the search area; range of vision: 2 cells; go upward a cell gradient of: nprey; cell final selection: the nearest one

\section{PredOneStage}

InitIng

my_ing : $=0$

My Cell -> aCell

From Cells to Animats -> aListOfAnimats

$\{$ returns all animats living on input cells\}

Select on name -> aListOfAnimats

\{Select objects (animats) of input list that match name: egg (Centro); N1-N4 (Centro) \}

To unroll a list $\rightarrow$ aAnimat

\{primitive: ToUnrollAList

$\{$ Returns one by one the objects (animats) of input list, and stops when list is over or when $m y \_$ing $>=m y \_$imax $\}$

Eat the prey $->$ aAnimat

$$
m y \_ \text {ing : }=m y \_ \text {ing }+i t s \_w e i g h t \text {; }
$$

Kill the prey

End - To unroll a list

\{ Cell definition \}

[ Entity]

OtherEntities \{primitive: ModifyAttributes

\{primitive: Kill $\}$

\{primitive: EndToUnrollAList 


\author{
[ Stages ] \\ Cell \\ [ Attributes ] \\ nprey $\quad$ \{number of prey\} \\ [ Tasks ] \\ Count in a Cell \\ \{user-defined task\} \\ Me $->$ aCell \\ \{primitive: $M e$ \} \\ All Animats -> aListOfAnimats \\ \{primitive: AllAnimats\} \\ \{returns all living animats \\ SelectOnName -> aListOfAnimats $\quad$ \{primitive: SelectOnName\} \\ \{Select objects (animats) of input list that match name: egg (Centro); N1-N4 (Centro)\} \\ Count -> aListOfAnimats \\ \{primitive: Count\} \\ \{Counts input items and puts the result in the attribute: nprey\}
}

\title{
Acknowledgments
}

The MOBIDYC platform (version 2.0) is freely available in French, English, and German and a tutorial (in French) is provided. It uses the Smalltalk Visual Works 7 environment developed by the Cincom Company. This environment is free for noncommercial use and runs on almost all platforms: http://www.avignon.inra.fr/mobidyc. This project aims to create a network group, which can participate in the improvement and development of these tools and also enrich the library of models. The models developed here can be downloaded (or obtained from S.S.) and immediately used. For example, biologists with in situ or experimental data who may like to test their own hypotheses can use this model as a starting point to adapt it to their own situation and obtain quick simulations. This work is a contribution to ELICO (Ecosystèmes Littoraux et Côtiers) and the contribution 4 of ECOREG (Ecosystem Complexity Research Group). We are very grateful to Volker Grimm and an anonymous referee for their helpful and constructive comments. We also thank Konstantinos Ghertsos and Peter G. Strutton for help with the English.

\section{References}

1. Ohman, M.D. and Hirche, H.-J., Density-dependent mortality in an oceanic copepod population, Nature, 412, 638, 2001.

2. Batchelder, H.P., Edwards, C.A., and Powell, T.M., Individual-based models of copepod populations in coastal upwelling regions: implications of physiologically and environmentally influenced diel vertical migration on demographic success and nearshore retention, Prog. Oceanogr., 53, 307, 2002.

3. Gaedke, U., Population dynamics of the calanoid copepods Eurytemora affinis and Acartia tonsa in the Ems-Dollart-Estuary: a numerical simulation, Arch. Hydrobiol., 118, 185, 1990.

4. Plagányi, É., Hutchings, L., Field, J.G., and Verheye, H.M., A model of copepod population dynamics in the Southern Benguela upwelling region, J. Plankton Res., 21, 1691, 1999.

5. Robinson, C.L.K. and Ware, D.M., Modelling pelagic fish and plankton trophodynamics off southwestern Vancouver Island, British Columbia, Can. J. Fish. Aquat. Sci., 51, 1737, 1994.

6. Bundy, M.H., Gross, T.F., Coughlin, D.J., and Strickler, J.R., Quantifying copepod searching efficiency using swimming pattern and perceptive ability, Bull. Mar. Sci., 53, 15, 1993.

7. Schmitt, F. and Seuront, L., Multifractal random walk in copepod behavior, Physica A, 301, 375, 2001.

8. Doall, M.H., Colin, S.P., Strickler, J.R., and Yen, J., Locating a mate in 3D: the case of Temora longicornis, Philos. Trans. R. Soc. Lond. B, 353, 681, 1998.

9. Pitchford, J.W. and Brindley, J., Prey patchiness, predator survival and fish recruitment, Bull. Math. Biol., 63, 527, 2001. 
10. Souissi, S., Carlotti, F., and Nival, P., Food and temperature-dependent function of moulting rate in copepods: an example of parameterization for population dynamics models, J. Plankton Res., 19, 1331, 1997.

11. Souissi, S. and Ban, S., The consequences of individual variability in moulting probability and the aggregation of stages for modelling copepod population dynamics, J. Plankton Res., 23, 1279, 2001.

12. Grimm, V., Wyszomirski, T., Aikman, D., and Uchmański, J., Individual-based modelling and ecological theory: synthesis of a workshop, Ecol. Modelling, 115, 275, 1999.

13. Fahse, L., Wissel, C., and Grimm, V., Reconciling classical and individual-based approaches in theoretical population ecology: a protocol for extracting population parameters from individual-based models, Am. Nat., 152, 838, 1998.

14. Lorek, H. and Sonnenschein, M., Modelling and simulation software to support individual-based ecological modelling, Ecol. Modelling, 115, 199, 1999.

15. Uchmański, J. and Grimm, V., Individual-based modelling in ecology: what makes the difference? TREE, 11, 437, 1996.

16. Grimm, V. and Uchmański, J., Individual variability and population regulation: a model of the significance of within-generation density dependence, Oecologia, 131, 196, 2002.

17. Railsback, S.F., Concepts from complex adaptive systems as a framework for individual-based modelling, Ecol. Modelling, 139, 47, 2001.

18. Grimm, V., Ten years of individual-based modelling in ecology: what have we learned and what could we learn in the future? Ecol. Modelling, 115, 129, 1999.

19. Judson, O.P., The rise of individual-based model in ecology, TREE, 9, 9, 1994.

20. Ginot, V., Le Page, C., and Souissi, S., A multi-agents architecture to enhance end-user individual based modelling, Ecol. Modelling, 157, 23, 2002.

21. Ferber, J., Multi-Agents Systems. An Introduction to Distributed Artificial Intelligence, Addison-Wesley, Reading, MA, 1999, 509.

22. Souissi, S., Modélisation du cycle de vie d'un poisson: conséquences pour la gestion des ressources exploitées. Application à l'étude de l'interaction entre les populations de copépodes et la population d'anchois. Ph.D. thesis, Université Pierre et Marie Curie Paris VI, Paris, 1998, 416 pp.

23. Souissi, S. and Uye, S.I., Simulation of the interaction between two copepods, Centropages abdominalis and Acartia omorii in an eutrophic inlet of the Inland Sea of Japan: role of predation and cannibalism, J. Plankton Res., in revision.

24. Uye, S.-I. and Liang, D., Copepods attain high abundance, biomass and production in the absence of large predators but suffer cannibalistic loss, J. Mar. Syst., 15, 495, 1998.

25. Liang, D., Uye, S.-I., and Onbé, T., Population dynamics and production of the planktonic copepods in a eutrophic inlet of the Inland Sea of Japan. I. Centropages abdominalis, Mar. Biol., 124, 527, 1996.

26. Liang, D., Uye, S.-I., and Onbé, T., Production and loss of eggs in the calanoid copepod Centropages abdominalis Sato in Fukuyama Harbor, the inland sea of Japan, Bull. Plankton Soc. Jpn., 41, 131, 1994.

27. Moloney, C.L. and Field, J.G., General allometric equations for rates of nutrient uptake, ingestion, and respiration in plankton organisms, Limnol. Oceanogr., 34, 1290, 1989.

28. Jager, H.I., Individual variation in life history characteristics can influence extinction risk, Ecol. Modelling, 144, 61, 2001.

29. Kendall, B.E. and Fox, G., Variation among individuals and reduced demographic stochasticity, Cons. Biol., 16, 109, 2002.

30. Burgman, M.A., Ferson, S., and Akcakaya, H.R., Risk Assessment in Conservation Biology, Chapman \& Hall, London, 1993.

31. Wissel, C., Stephan, T., and Zaschke, S.-H., Modelling extinction and survival of small populations, in Minimum Animal Populations, Remmert, H., Ed., Springer, Berlin, 1994, 67.

32. Schmitt, P.D., Prey size selectivity and feeding rate of larvae of the northern anchovy, Engraulis mordax Girard, CalCOFI Rep., 27, 153, 1986.

33. Caparroy, P., Thygesen, U.H., and Visser, A.W., Modelling the attack success of planktonic predators: patterns and mechanisms of prey size selectivity, J. Plankton Res., 22, 1871, 2000.

34. Houssin, D., Bornhofen, S., Souissi, S., and Ginot, V., Entre programmation par composants et langages d'experts: Mobidyc, une plate forme multi-agents orientée utilisateur pour la dynamique des populations, Tech. Sci. Inf., 21, 525, 2002.

35. Lomnicki, A., Population ecology from the individual perspective, in Individual-Based Models and Approaches in Ecology, DeAngelis, L. and Gross, L.J., Eds., Chapman \& Hall, New York, 1992, 3. 
36. Schmitz, O.J., Combining field experiments and individual-based modeling to identify the dynamically relevant organizational scale in a field system, Oikos, 89, 471, 2000.

37. Levin, S.A. and Durrett, R., From individuals to epidemics, Philos. Trans. R. Soc. Lond. B, 351, 1615, 1996.

38. Wilson, W.G., Lotka's game in predator-prey theory: linking populations to individuals, Theor. Pop. Biol., 50, 368, 1996.

39. Sumpter, D.J. and Broomhead, D.S., Relating individual behaviour to population dynamics, Proc. R. Soc. Lond. B, 268, 925, 2001.

40. Berec, L., Techniques of spatially explicit individual-based models: construction, simulation, and mean-field analysis, Ecol. Modelling, 150, 55, 2002.

41. Wilson, W.G., Resolving discrepancies between deterministic population models and individual-based simulations, Am. Nat., 151, 116, 1998.

42. Minar, H., Burkhart, R., Langton, C., and Askenazi, M., The swarm simulation system: a toolkit for building multiagent simulations, Santa Fe Institute Working Paper 96-06-042, 1996.

43. Mamedov, A. and Udalov, S., A computer tool to develop individual-based models for simulation of population interactions, Ecol. Modelling, 147, 53, 2002.

44. Laval, P., Hierarchical object-oriented design of a concurrent, individual-based, model of a pelagic tunicate bloom, Ecol. Modelling, 82, 265, 1995.

45. Laval, P., A virtual mesocosm with artificial salps for exploring the conditions of swarm development in the pelagic tunicate Salpa fusiformis, Mar. Ecol. Prog. Ser., 154, 1, 1997.

46. Mooij, W.M. and Boersma, M., An object-oriented simulation framework for individual-based simulations (OSIRIS): Daphnia population dynamics as an example, Ecol. Modelling, 93, 139, 1996.

47. Sciandra, A., Study and modelling of development of Euterpina acutifrons (Copepoda, Harpacticoida). J. Plankton Res., 8, 1149, 1986.

48. Souissi, S. and Nival, P., Modeling of population dynamics of interacting species: effect of exploitation, Environ. Model. Assess., 2, 55, 1997.

49. Carlotti, F. and Wolf, K.-U., A Lagrangian ensemble model of Calanus finmarchicus coupled with a 1-D ecosystem model, Fish. Oceanogr., 7, 191, 1998.

50. Uchmański, J., What promotes persistence of a single population: an individual-based model, Ecol. Modelling, 115, 227, 1999.

51. Miller, C.B., Lynch, D.R., Carlotti, F., Gentleman, W., and Lewis, C.V.W., Coupling of an individualbased population dynamic model of Calanus finmarchicus to a circulation model for the Georges Bank region, Fish. Oceanogr., 7, 219, 1998.

52. Abraham, E.R., The generation of plankton patchiness by turbulent stirring, Nature, 391, 577, 1998.

53. Folt, C.L. and Burns, C.W., Biological drivers of zooplankton patchiness, TREE, 14, 300, 1999.

54. Seuront, L. and Lagadeuc, Y., Multiscale patchiness of the calanoid copepod Temora longicornis in a turbulent coastal sea, J. Plankton Res., 23, 1137, 2001.

55. Tsuda, A., Sugisaki, H., and Kimura, S., Mosaic horizontal distributions of three species of copepods in the subarctic Pacific during spring, Mar. Biol., 137, 683, 2000.

56. Bernard, O. and Souissi, S., Qualitative behavior of stage-structured populations: application to structural validation, J. Math. Biol., 37, 291, 1998.

57. Fennel, W., Modeling of copepods with links to circulation models, J. Plankton Res., 23, 1217, 2001.

58. Pedersen, O.P., Tande, K.S., and Slagstad, D., A model study of demography and spatial distribution of Calanus finmarchicus at the Norwegian coast, Deep Sea Res. II, 48, 567, 2001.

59. Franks, P.J.S. and Jaffe, J.S., Microscale distributions of phytoplankton: initial results from a twodimensional imaging fluorometer, OSST, Mar. Ecol. Prog. Ser., 220, 59, 2001.

60. Wolk, F., Yamazaki, H., Seuront, L., and Lueck, R. G., A new free-fall profiler for measuring biophysical microstructure, J. Atmos. Ocean. Tech., 19, 780, 2002. 